\title{
Research on Teaching Practice of College English PAD Class with Multi-Modality plus Mutual Evaluation
}

\author{
Huijian Wang, Huijun Fu, Dan Wang \\ College of Foreign Language Education and International Business, Baoding University, Baoding, China \\ Email: lanyu2003flower@163.com
}

How to cite this paper: Wang, H. J., Fu, H. J., \& Wang, D. (2021). Research on Teaching Practice of College English PAD Class with Multi-Modality plus Mutual Evaluation. Creative Education, 12, 966-973. https://doi.org/10.4236/ce.2021.125070

Received: April 19, 2021

Accepted: May 8, 2021

Published: May 11, 2021

Copyright $\odot 2021$ by author(s) and Scientific Research Publishing Inc. This work is licensed under the Creative Commons Attribution International License (CC BY 4.0).

http://creativecommons.org/licenses/by/4.0/

\begin{abstract}
College English class in Presentation-Assimilation-Discussion style can not only benefit the multi-faceted input of information in language teaching, but also pay attention to students' language output and enhance their self-confidence. This paper introduces a teaching action research in Presentation-Assimilation-Discussion style with multi-modality plus mutual evaluation on the basis of research background and studies on PAD class in China, so as to provide a new perspective for the construction of college English PAD class, to build a new mode of discussion based on teaching APP, and improve the effectiveness of college English teaching.
\end{abstract}

\section{Keywords}

PAD Class, College English, Multi-Modality, Mutual Evaluation

\section{Introduction}

PAD class is a teaching innovation with Chinese characteristics proposed by Professor Zhang Xuexin of the Department of Psychology of Fudan University based on psychology (Zhang, 2014). The PAD class divides teaching into three processes that are clearly separated in time, namely presentation, assimilation and discussion (abbr. PAD). Its innovation lies in "separate discussion", that is, separating lectures and discussions, allowing students to have a certain period of independent learning between the two, in order for students to assimilate knowledge in their own style (Zhang, 2016).

\section{Literature Review}

With "PAD class" as the key word, 1150 journal papers were found on CNKI, 
including the development and design of PAD class, the feasibility analysis of the use of PAD class, and the application of PAD class in different courses and teaching practice of it, involving psychology, pedagogy, English, ideology and culture, chemistry, physics, electrical engineering, traditional Chinese medicine, nursing etc. covering wide subjects from high school to postgraduate courses. However, only 47 papers were found with the key words "College English Teaching" in the results, covering the feasibility analysis of the application of the PAD class theory in college English teaching; the process of application and teaching practice in writing, reading, translation, reading and writing, (Wang, 2021) etc.

After the publication of Professor Zhang Xuexin's "PAD Class: A New Attempt in University Teaching Reform" in 2014, the research on the exploit and design of PAD class began gradually. With the deepening of the research, the researchers also gave some new ideas to PAD class. For example, there are the construction and application of combination of Internet plus and PAD class (Guo, 2017), the combination of CBI teaching concepts and PAD class, the blended teaching model of "micro-class plus PAD class" and "flipping plus PAD class" (Qu \& Li, 2018), etc. The integration of these concepts and PAD class enriches the teaching methods of the PAD class, and also enables the two parties to promote each other's development, and provides new ideas and ways for the PAD class to be used in the actual teaching.

To sum up, the PAD class is increasingly recognized by teachers and applied to the actual teaching in China. However, the current research on PAD is mainly based on analysis of application and practice, and there are few empirical studies. There are few studies on how to determine the teaching content and content system, and how to assist students to assimilate in a certain amount of time after class, how to carry out classroom discussion and how to conduct immediate and effective evaluation, so it is necessary to carry out further study.

\section{Teaching Practice of College English PAD Class with Multi-Modality plus Mutual Evaluation}

\subsection{The Definition of College English PAD Class with Multi-Modality plus Mutual Evaluation}

It's a new mode of Presentation-Assimilation-Discussion classroom, adopting the advanced technology to create multi-modal college English teaching methods and resources that integrate teaching materials, mobile teaching groups, mobile terminal teaching APP and network teaching platform to build,

\subsection{Action Research on PAD Class Teaching with Multi-Modality plus Mutual Evaluation}

\subsubsection{Research Subject}

This research lasted from September 2019 to December 2020, and the research subjects are the college students majoring in Ideological and Political Education. The students have a good language foundation and strong learning motivation. 
Most students can actively cooperate with the teacher's classroom teaching and complete the relevant learning tasks arranged before and after class.

\subsubsection{Research Methods}

This research mainly adopts the method of action research, collecting data and information through questionnaire surveys and student interviews, designs PAD class teaching with multi-modality plus mutual evaluation and carries out the research through planning, action, observation and reflection.

\subsubsection{Research Process}

This research consists of two phases, (the original plan has three phases, due to the impact of COVID-19, the second and third phases are merged.) They are multi-modal college English PAD class teaching practice, and PAD class teaching practice with multi-modality plus mutual evaluation.

The first stage (2019.9-12): Multi-modal college English PAD class teaching practice. In the teaching process, the teacher adopted the advanced technology, rationally integrated and used the Unipus teaching platform, Ucampus APP, campus network teaching platform (Chaoxing Xuetong) and other multi-modal college English teaching methods and resources, and constructed a multi-directional and three-dimensional interaction teaching process, including the interactive activities between teachers and students, students and students as well as the interaction of knowledge and ability in and out of class.

\section{Action design}

The teacher determines the content of classroom teaching according to the College English syllabus and the understanding and processing of the teaching materials. Students are provided with multi-modal learning resources and references online and offline, and given a specific period of time to study independently after class to achieve internal assimilation. According to the important and difficult points in teaching, the teacher determines the online or offline discussion tasks (or themes), the form of discussion and presentation of the achievements, so that students can participate in classroom activities. The ratio between teacher's presentation and class discussion is 7:3.

\section{Program implementation}

The teacher determined and presented the content and key and difficult points of the class according to the syllabus, subject type, article genre framework, grammar knowledge, vocabulary modules, and language skills, and determine the discussion tasks (topics), forms of discussion, and forms of presentation of the achievement according to the important and difficult points, provided students with online multi-modal learning resources and references with the help of the Unipus teaching platform, Ucampus APP, and Chaoxing Xuexitong APP. Students were given a week to study independently after class to achieve internal absorption. Students got more opportunities to communicate and explore English online and offline, complete common and personalized homework, deepen their understanding and mastery of teaching content, and 
truly become the main body of college English learning. Class discussion mainly includes two forms: in-group discussion and inter-group discussion. One of the them each time. Students can introduce their masted knowledge, speeches, posters, role performances, etc. according to the task set before.

\section{Observation and discovery}

Through one semester's observation, students' performance in PAD class teaching has changed significantly: 1) Students' understanding and mastery of English knowledge have been improved, and they have more analysis and thinking on problems; 2) The participation of students in class discussions has increased. Some students were at a loss about the discussion tasks and discussion rules at first, but they can basically participate in it after two months; 3) The classroom atmosphere became more and more harmonious with the enhancement of the classroom interaction, such as teacher-student interactions and student-student interactions, online and offline interactions, and the interaction in and out of the classroom and the teaching effect was also improved.

\section{Reflection}

Through the action intervention at this stage, the author has a more dialectical understanding of the PAD class.

1) The "dual subject" role of teachers and students should be highlighted. Teachers should focus on the two main subjects of teachers and students in the selection of teaching content, respecting the irreplaceable role of teachers in teaching as well as respecting the rights and interests of students, and playing the master status of students. Teachers determine the content and key difficulties of classroom teaching according to the characteristics of the textbook and the learning needs of students, which can not only ensure the effective transmission of the knowledge system, but also ensure that students can draw a clear distinction between the primary and the secondary in the process of learning, internalization, and discussion, which is more targeted. Students become the real learning participants instead of a listener.

2) Hierarchical and personalized assignment. In addition to the regular common homework, there is also personalized homework named "Bright-Test-Help", which focuses on cultivating students' personalized development and can promote a virtuous circle of learning. At the same time, it is emphasized that learning is based on the system of subject to form the learner's own cognitive structure, not only to master English knowledge, but also to cultivate English language thinking ability.

The first stage of action intervention has improved most students' understanding and assimilation of English knowledge. They can accurately understand and prepare for class discussion tasks. The participation in class discussion has been significantly improved, but the time for class discussion is short, and students' discussions and communication are not deep enough. Because the evaluation is not timely, the students cannot get the feedback they need, and they cannot correct the mistakes in time. Therefore, in the second stage of action intervention, the teacher needs to consider adjusting the ratio of time on presentation 
and discussion, and how to make students get objective evaluation and feedback through instant mutual evaluation to make class discussions more effective.

The second stage (2019.9-12): PAD class teaching practice with multi-modality plus mutual evaluation. On the basis of Multi-modal college English PAD class teaching practice, a mutual-evaluation PAD class teaching is constructed based on the adoption of Chaoxing Xuetong APP.

\section{Action design}

On the basis of the original multi-modal college English PAD class teaching, the time for class discussion is increased, and student mutual evaluation is added on the basis of teaching APP. The time ratio of teachers' presentation and class discussion is 5:5.

\section{Program implementation}

The teacher recorded and monitored the learning process of students through the Chaoxing Xuexitong teaching APP. The teacher formulated an independent learning evaluation system and evaluation standards and paid attention to motivation-based process evaluation, focusing on students' dedication to learning, and recognizing and protecting students' personalized differences in learning. According to the mutual evaluation system and standards, students conduct effective mutual evaluations of peers' learning and performance in-class discussions or online discussions by quantitative scores and comments.

\section{Observation and discovery}

Through observations in one semester, it was found that 1) Due to the relatively sufficient time for class discussion, student can discuss more comprehensively and deeply. The combination of intra-group discussion and inter-group discussion not only improved the courage of students, but also enhanced the cohesion and sense of mission of team members. They can not only exercise their oral English ability, but also try to learn from others' perspectives and inspire each other; 2) Immediate peer evaluation improves students' enthusiasm for classroom participation. Teachers can make full use of the function of homework peer evaluation on the mobile teaching APP in the classroom, so that students can not only submit immediately, but also view the work of all the students in the class, and complete peer evaluation by quantitative grading and comments to the students in the group or randomly. On the one hand, it can increase the interaction and supervision between peers and help learners get instant and diversified homework feedback. On the other hand, while ensuring the teacher's initiative in homework checking, it does not increase the workload, achieving a win-win situation for both teachers and students.

After the second phase of the action research, questionnaire surveys and interviews were conducted with the students. The questionnaire was presented in the form of a five-level scale with five questions in total and 80 students participating in the action research were surveyed. 80 questionnaires were distributed and 80 copies all of them were recovered, the recovery rate was $100 \%$, and the effective rate was $100 \%$. Regarding the question "Do you like PAD class", $95 \%$ of the students chose to like it. They believed that this approach gave them more 
initiative and improved their autonomous learning awareness and ability. Regarding teacher's presentation, $80 \%$ of students believe that the key points of the lectures are prominent and the learning is more targeted. In the stage of assimilation, students could allocate time reasonably according to their personal needs to achieve personalized learning. More than $90 \%$ of the classmates think that the class discussion session can help them expand their thinking, from vocabulary expansion to expression of point of view. More than $95 \%$ of the students believe that the mutual evaluation process encourages them to listen to their students more seriously and more carefully so that they can evaluate their peers objectively and effectively.

\section{Reflection}

Through the action intervention at this stage, the author found the following situations in the link of evaluation.

1) Compared with the qualitative evaluation of comments, students are more willing to participate in quantitative evaluation, and there are situations where the evaluation standards are not strictly implemented and emotional scores are given. Therefore, teachers need to guide students to score objectively and reasonably; 2) The students' analysis is not comprehensive enough in the qualitative evaluation, and the comments are not targeted. So teachers need to demonstrate and guide them; 3) Student-student evaluation alone cannot provide students with comprehensive and accurate feedback. It is necessary to build a multi-modality evaluation, integrating teacher-student evaluation, student-student evaluation, and group evaluation, so that students can obtain comprehensive feedback, which is more conducive to adjustment and improvement.

\section{Teaching Enlightenment}

College English PAD class can strike a balance between the concepts of "teacher-centered" and "student-centered". It is not only conducive to the multi-faceted information input of language teaching, which can fully guarantee students' language practice, but also emphasizes language output which makes students feel their progress, enhances their self-confidence and promotes personalized learning, deep learning and creative learning, thereby improving the effect of college English teaching.

1) Changing the concept of teachers. An important problem to be solved in constructing a college English PAD class with multi-modality plus mutualevaluation is to change teachers' concepts. Teaching is a bilateral activity, and the classroom is not a stage for teachers only. Instead, it must be set aside half for students, and empower them to be a manager of their English learning. Teachers' presentation in the classroom should only be guided and targeted lectures, with intensive lectures and blank spaces, rather than comprehensive coverage of knowledge.

2) Attaching importance to knowledge reserves. In college English class discussions, due to time constraints, students are often nervous, incoherent and 
unable to accurately organize and express true thoughts, not to mention the exchange and sharing of information or the expansion of knowledge when they are unable to fully think and have insufficient information, which makes it more difficult to achieve the expected purpose. The PAD class gives students a certain amount of time to internalize and assimilate knowledge, which can make good preparation for classroom discussions, thereby protecting students' interest and enthusiasm in learning, and promoting a virtuous circle of English learning.

3) Increasing immediate feedback. In college English teaching, in most cases, teachers use summative evaluation and procedural evaluation to evaluate students' learning behaviors and learning effects, but these evaluations cannot be fed back to students immediately. In addition, it is difficult for English teachers to provide immediate feedback on the learning performance of each student in the classroom discussion session of large-scale English teaching. None of the above situations can achieve feedback and evaluation to stimulate and guide students in the learning process. While ensuring teachers' initiative in checking homework, empower students to use mobile teaching apps in the class discussion to evaluate peers' performance in discussions based on the mutual evaluation system and standards, which will help learners obtain instant and diversified feedback, which can further improve students' enthusiasm and initiative in learning English in class and after class, and improve students' participation in class discussion and the quality and effect of class discussion.

\section{Conclusion}

The exploration and practice of college English PAD class with multi-modality plus mutual evaluation is a new research of making full use of information and Internet technology in the era of big data. It is a new attempt to reform college English teaching in applied local undergraduate colleges. This model not only emphasizes teaching before learning, but also greatly highlights the main role of students in discussion-based learning. It emphasizes student-student interaction, teacher-student interaction, and encourages independent learning and individualized learning. Therefore, the roles of teachers and students are more distinct, which not only enhances students' initiative in learning but also highlights the guiding role of teachers. The teaching process is clearer and students' learning goals are clearer. Both the teaching time and teaching rights and responsibilities can be divided equally, which can change students' passive state and the lack of communication opportunities between teachers and students in traditional college English classroom and can more effectively improve the efficiency of college English learning, so it has application value.

In the classroom presentation, the teacher can give appropriate and targeted explanations according to students' demands; after class, multi-modal digital resources and teaching methods are introduced into the stage of internalization and absorption, which can deepen students' understanding of what they have learned visually and intuitively according to the characteristics of teaching mate- 
rials, the flexible selection of online and offline discussions is more conducive to cultivating interest in English learning according to the characteristics of college English; the adoption of process evaluation, which pays more attention to s development of students' English learning habits and emphasizes the outstanding role of peer review, helps learners to obtain diversified homework feedbacks. All of these will help change the phenomenon of college students' English learning burnout, and improve college students' English autonomous learning ability, critical thinking ability, and negotiation and cooperation ability. So, it is of great practical significance for the improving of college English teaching effect, hoping that it can attract more and more college English teachers take part in the research of this field and provide more reference for the practice of English PAD class.

\section{Project}

This article is one of the research results of the English teaching reform research and practice project of Hebei Provincial Department of Education in 2019, project number: 2019YYJG058

\section{Conflicts of Interest}

The authors declare no conflicts of interest regarding the publication of this paper.

\section{References}

Guo, S. R. (2017). Research and Practice on the Flipped Teaching Mode Based on "Internet + PAD Class". Heilongjiang Education (Theory \& Practice), 3, 39-41.

Qu, H. L., \& Li, X. Y. (2018). The Practice of Flipped Classroom and Halved Classroom Based on Micro-Class in Teaching. Continuing Medical Education, 41, 76-80.

Wang, X. (2021). Research on the Application of PAD Class Mode into Reading Teaching of English Majors. Journal of Heilongiiang Institute of Teacher Development, 40, 135-137

Zhang, X. X. (2014). PAD Class: A New Attempt in University Teaching Reform. Fudan Education Forum, 12, 5-10.

Zhang, X. X. (2016). The PAD Class: New Wisdom of Chinese Education. Beijing: Science Publishing. 